GONZALES JAUREGUI, Yobani Maikel (...) USP - Ano IX, n. I4, p. 67-97, 2018

\title{
La Confederación Perú-boliviana y las oposiciones políticas y económicas en la región del Pacifico sur
}

\author{
Yobani Maikel Gonzales Jauregui
}

Doctorando en História por la Universidade Federal de Juiz de Fora (UFJF)

\section{Resumen}

El presente artículo analizara el proyecto político y económico que implementó el general Andrés de Santa Cruz durante la Confederación Perú-boliviana, generando dos oposiciones muy claras. La oposición política encabezada por el general Agustín Gamarra y los emigrados y la oposición económica, liderada por el Estado chileno. Que desde la prensa atacó sin tregua al proyecto confederado y a su artífice, afirmando que este nuevo Estado quebraba su hegemonía en el Pacífico sur, apoyando decididamente la intervención bélica que los emigrados le propusieron.

Palavras claves Andrés de Santa Cruz, Perú, Bolivia, Chile, Libre Comercio.

\begin{abstract}
This article will analyze the political and economic project implemented by General Andrés de Santa Cruz during the Peru-Bolivian Confederation, generating two very clear oppositions. The political opposition led by General Agustín Gamarra and the emigrants and the economic opposition, led by the Chilean State. That from the press he attacked the Confederate project and its architect, affirming that this new State broke its hegemony in the South Pacific, decisively supporting the military intervention proposed by the emigrants.
\end{abstract}

Keywords Andrés de Santa Cruz, Peru, Bolivia, Chile, free trade 


\section{Introducción}

En este artículo nos interesa analizar el proyecto político y económico que el general Andrés de Santa Cruz estableció durante la conformación y desarrollo de la confederación Perú-boliviana. Siendo desde nuestra perspectiva el primer proyecto articulado sobre el Estado en el Perú del siglo XIX. Este proyecto liberal en materia económica, pero autoritario en lo político tuvo como uno de sus ejes el fortalecimiento de los regionalismos, dividiendo al Perú en dos espacios regionales. El estado nor-peruano y el estado sud peruano, este último encajaba perfectamente con el norte de Bolivia, porque era espacios con semejanzas e intereses en común desde la época colonial. En tanto, que, el norte peruano y Lima representaban la oposición al proyecto confederado, debido a que la apertura comercial que promovía la política liberal de Santa Cruz perjudicaba el monopolio de poder de la elite de Lima y de los hacendados norteños, quienes tenían un intercambio comercial muy fluido con Chile. Además que existían algunas ideas de trasladar la capital hacía el Cusco perjudicando a la elite limeña.

En el sur peruano no existía una posición unitaria en torno al federalismo, uno de los pocos espacios federalistas y liberal se encontraba en Arequipa, que desde antes del inicio del proyecto confederado ya proclamaba su interés en vincularse en una federación con Bolivia. Otras ciudades como Cusco y Puno van siendo favorables al federalismo con el desarrollo de los acontecimientos políticos y de acuerdo a los beneficios que podrían obtener en el nuevo mapa político.

Otro punto de interés es analizar las medidas comerciales que se aplicaron durante la corta vida del gobierno confederado y que son el elemento central que nos permite caracterizar a la confederación Perú Boliviana como un proyecto liberal, porque se firmaron tratados de libre comercio con Inglaterra y Estados Unidos, se modernizaron los puertos, se eliminaron aranceles y las exportaciones de azúcar fueron creciendo progresivamente. Todas estas medidas generaron una relativa paz social y económica, inexistente hasta esa fecha, desafortunadamente nuestro tránsito a la vida republicana estuvo marcado, por una época de caos y una permanente inestabilidad política, evidenciado en la constante lucha entre caudillos por el poder.

Es a partir, de la aplicación de las medidas económicas y de la propia conformación de la Confederación Perú-boliviana que se generaron dos oposiciones al proyecto confederado, una política encabezada por Gamarra y diversos sectores de la elite limeña y una oposición comercial que era liderada por Chile. Estos dos intereses convergieron para destruir 
GONZALES JAUREGUI, Yobani Maikel (...) USP - Ano IX, n. I4, p. 67-97, 2018

al proyecto confederado, Gamarra deseaba establecer una unión con Bolivia, pero que implicaría desaparecerla y Chile recelaba de las efectivas medidas económicas que estableció el general Santa Cruz lo que hacía peligrar su hegemonía en el Pacifico sur, como se señalaba en diversas ediciones del periódico El Araucano.

\section{La economía liberal del proyecto confederado}

Durante los primeros años de vida independiente, el Perú adoptó un modelo económico llamado nacionalismo económico. Esta corriente económica que se expresaba en el proteccionismo rechazaba la incursión extranjera en la economía nacional. Se elevaron los aranceles, en algunos casos hasta el $200 \%$ para productos agrícolas provenientes de las economías centrales. Al parecer, no siempre se buscaba proteger la pobre industria local lo que escondían estas medidas era captar más dinero debido a que la elite a pesar de lo costoso que podría resultar el producto lo seguiría comprando porque era una forma de distinción social. Así lo señala Carlos Contreras:

Los aranceles proteccionistas que dominaron el Perú virtualmente a lo largo del siglo XIX, pero de manera clara hasta 1864, partieron de la idea que el apogeo al consumo de bienes importados por parte de la clase propietaria era tal que las ventas no se resentirían a pesar de los elevados impuestos. Las importaciones tenían una demanda inelástica, para expresarlos en términos económicos. El propósito de la política de aranceles elevados, no habría sido entonces, tanto la protección de una industria nacional, verdaderamente inexistente, cuando la obtención de recursos fiscales de ese grupo social. ${ }^{1}$

Creemos que si bien se mantuvo una política arancelaria fuerte con los productos suntuarios, no fue así con productos como la harinas, tocuyos o telares que fueron prohibidos de ingresar al país, por la fuerte oposición de los comerciantes del Consulado de Lima, que solo querían un comercio con Chile a quien consideraban un socio estratégico. Esta etapa del florecimiento del proteccionismo económico se sostuvo por la necesidad de los caudillos de congraciarse con los comerciantes agrupados en el poderoso tribunal del consulado de Lima, que otorgaba fuertes cantidades de dinero a cambio de políticas económicas que protegieran la producción de harina, textiles sencillos, mantecas, muebles toscos, tabaco y algodón, y demás productos provenientes de Estados Unidos, Gran Bretaña y Francia.

I CONTRERA, Carlos. Aprendizaje del Capitalismo. Estudios de Historia Económica y Social del Perú Republicano. Lima: IEP, p. 70. 


\section{R E V I S T A A N GELUS N O V U S}

Los comerciantes peruanos promovían un libre comercio sólo con Chile, considerándolo un socio estratégico, fortaleciendo los vínculos que se tenían desde la época colonial, al cual vendían azúcar y compraban trigo. Por otro lado, las potencias extranjeras como Estados Unidos, Gran Bretaña y Francia, enviaron cónsules y ministros plenipotenciarios para persuadir a las autoridades de las nacientes repúblicas de las bondades del libre comercio, las actitudes iban desde la política más agresiva representada por los Estados Unidos, la diplomática por Inglaterra y los despliegues de fuerza militar que hacían los franceses. Los Estados Unidos jugó un papel crucial en estos años, el Perú representaba dentro de la política estadounidense un socio comercial estratégico, por ello no escatimaron esfuerzos en desplegar a través de campañas de su prensa aliada defensas ardorosas al libre comercio, estos hechos reforzaron la posición nacionalista, porque la prensa limeña atacó la intromisión extranjera, como también a los autores de los escritos librecambistas a quienes los acusaban de anti-patriotas.

Estos debates fueron seguidos de cerca por los ministros plenipotenciarios enviados por los americanos, entre los que destaca el ministro Larned, quien tenía mucha cercanía con José María Pando, a quien buscaba persuadir para lograr preferencias arancelarias y firmar un acuerdo comercial con su país. Sin embargo, la inestabilidad política reinante fue un grave problema, porque no permitió que una política librecambista tuviera el éxito esperado. Paúl Gootenberg, ha sido quien mejor ha graficado este punto afirmando que:

La alternativa de trabajar dentro de estructuras políticas sumamente inestables probó ser igualmente infructuosa. Como los Estados Unidos descubrieron, el cultivo de aliados, la manipulación de líderes, los esfuerzos de propaganda y otros objetivos políticos se frustraron cuando los políticos, funcionarios e instituciones a los que se dirigían, se evaporaron, desaparecieron, o se escaparon por razones de seguridad. ${ }^{2}$

Este mismo autor esgrime otros factores que impidieron el triunfo de un sistema de libre comercio en el Perú a inicios de la vida republicana, entre los que destaca la debilidad del Estado:

Que hizo que las diversas formas de resistencias fueran efectivas: caudillos que mantenían corrientes nativistas al mando, o la facilidad de los nacionalistas en bloquear, atascar paralizar y eliminar iniciativas de evanescentes comités y congresos. El resultado final fue la impotencia de los influyentes Cusco: CBC, p. 96. 
GONZALES JAUREGUI, Yobani Maikel (...) USP - Ano IX, n. I4, p. 67-97, 2018 colaboradores, que probaron ser completamente incapaces de controlar los acontecimientos y que internalizaron la amenaza nacionalista para sí mismos. ${ }^{3}$

El librecambismo tuvo época primaveral en el gobierno del general José Luis Orbegoso y alcanzó su apogeo durante la confederación Perú-boliviana, siendo en este último periodo donde se intentará seriamente implementar un libre comercio con las potencias como Estados Unidos y Gran Bretaña. El presidente Orbegoso había sentado las bases económicas del proyecto liberal al anular el tratado de preferencias arancelarias que él mismo había firmado -y que el gobierno del general Salaverry ratificó con el gobierno chileno- porque perjudicaba la apertura comercial y la supremacía del Callao. Por lo tanto, se determinó:

Que uno de los puntos cardinales de la política del gobierno peruano, debe ser el fomentar su comercio directo con el Europa, Estados Unidos y los demás pueblos del globo, y que este objeto no podrá lograrse existiendo el tratado celebrado con Chile en I835, porque este país posee ventajas naturales que serán entonces más poderosas, y que imposibilitaría la resurrección de la antigua supremacía comercial del Callao sobre los demás puertos del Pacifico. ${ }^{4}$

Las protestas desde Chile no se hicieron esperar, la anulación del contrato desde su perspectiva no solo era perjudicial para ellos, sino para la economía de todos los Estados de Sudamérica porque:

Los pueblos americanos debemos promover nuestros intereses recíprocos y crear vínculos que ligando poderosamente a las nuevas repúblicas... el comercio, la industria, la agricultura, todos los ramos de la riqueza y de la ventura publica están todavía en la cuna, como nuestra organización política. Todo necesita de protección y de fomento para mejorar.... Estos principios eminentemente americanos guían la política de la administración chilena. ${ }^{5}$

Qué duda cabe que el principal objetivo de Chile para oponerse a la confederación era la política comercial que se estaba implementando. Un viajero sueco de la época, Carl August Gosselman, ${ }^{6}$ señalaba que la verdadera causa de la guerra entre Perú y Chile era la no ratificación del tratado comercial firmado entre ambos países, debido a que Chile perdía las

3 GOOTENBERG, Paul. Op. cit. p. 96.

4 Mercurio de Valparaiso, 4 de julio de I836, p. 4.

5 El Araucano. Santiago de Chile, 28 de Agosto de 1836.

6 TAURO, Alberto. Viajeros en el Perú republicano. Lima: UNMSM. 1967, p. 48. 


\section{R E V IS TA A N GELUS NOVU S}

ventajas sobre el Perú, por ese motivo el presidente Orbegoso anuló dicho tratado generando las encendidas criticas de Diego Portales, para quien existía además los celos personales de ver:

gobernar en el Perú a un hombre que, partiendo de los mismos prudentes principios (liberales) ha colocado ya a Bolivia en un estado de florecimiento y que, al mismo tiempo que empezaba a ayudar al Perú a vencer su debilidad comercial necesariamente debía con ellos reducir la superioridad que Chile se había arrogado sobre el hasta peor gobernado país vecino. La importancia de Valparaíso como puerto de depósito para casi toda la costa occidental de Sudamérica necesariamente había de disminuir tan prontamente gozasen de esta ventaja otros puertos y muy principalmente el del Callao, que es sin punto de comparación un puerto mejor que el de Valparaíso. ${ }^{7}$

Esta percepción refleja el caos que imperaba en el Perú, que había llevado al Callao a perder su lugar privilegiado en el pacífico sur, si bien tenía una mejor ubicación que su vecino chileno, las malas decisiones políticas y económicas habían sumido en la crisis al principal puerto peruano. Es la llegada de Santa Cruz que permitió recuperar el espacio perdido y mejorar realmente las finanzas del caótico estado peruano. Este hecho activó los recelos del país sureño, que, por todos los medios, intento poner fin al estado confederado, convirtiéndose en cuestión de Estado acabar con el proyecto confederado, porque en el aspecto económico, la unión significaba la pérdida de privilegios económicos con el Perú. En ese sentido, la administración chilena buscaba beneficiar su economía y no tuvo reparos en negociar un tratado comercial con Salaverry, que había llegado al poder asaltando la silla del gobierno:

sin el menor miramiento a la ilegalidad de la autoridad con quien trataba, ratificó, canjeó con ésta el Tratado del 20 de enero de 1835 ... y lo práctico así, tan sólo porque convenía a sus intereses, dando prueba de su inmoralidad y de su simpatía por una autoridad de tan bastardo origen como la de Prieto en Chile. ${ }^{8}$

La prensa chilena elevó su voz de protesta por la anulación del tratado señalando que el tratado no era más ventajoso para Chile y que la importancia de Valparaíso se había desarrollado de forma espontánea al abrirse Cabo de Hornos al comercio marítimo. Además, la ventaja chilena en la balanza comercial se presentaba de forma natural, no era buscada por Chile. ${ }^{9}$ Es evidente que los intereses del gobierno de Chile no suponían el respeto por una

7 TAURO, Alberto. Viajeros en el Perú republicano. Lima: UNMSM. 1967, pp. 48-49.

8 SANTA CRUZ, Oscar. El General Andrés de Santa Cruz. Gran Mariscal de Zepita y el Gran Perú. La Paz, I924, p. I23.

9 Mercurio de Valparaiso, 4 de Julio de 1836. 
GONZALES JAUREGUI, Yobani Maikel (...) USP - Ano IX, n. I4, p. 67-97, 2018 autoridad legítima sino por aquella que estuviera a lado de sus intereses por eso no dudó en buscar un trato con el gobierno de Salaverry y cuando Orbegoso retomaría el poder intentaría que el tratado de comercio consiga una ampliación. Argumentando que el acercamiento al gobierno breve de Salaverry se basaba en el caos y la inestabilidad política del Perú, que impedía conocer quién era la autoridad legítima:

Estábamos pues autorizados para mirar el orden de cosas a que dio principio el general Salaverry como una de las varias fases que ha tomado la revolución en el Perú, y no nos hallábamos en el caso de escudriñar su origen y examinar sus títulos. Nos atenemos a la superficie de los hechos; no era nuestro deber, ni el interés del Estado chileno pasar más allá. ${ }^{\text {Io }}$

Para Diego Portales, el caos en el Perú no invalidaba la ratificación del tratado porque no era responsabilidad del gobierno Chile darle la legitimidad a una de las facciones que se disputaban el poder, sino que esa función le correspondía al pueblo peruano. Por lo tanto, era innecesario culpar a Chile del trato que mantenía con las dos facciones. Sin embargo, Orbegoso consideraba que el tratado no era equitativo y solo lo extendió por cuatro meses más, enciendo las críticas del gobierno chileno, que perdía un socio comercial estratégico, este hecho reavivó las críticas del gobierno de Chile, así lo demuestra el discurso del presidente Prieto, quien afirma que:

A consecuencia de los últimos sucesos que han ocurrido en el Perú, la ratificación de nuestro tratado con aquella República ha sido declarada de ningún valor por la administración peruana que reemplazó a la del general Salaverry; y la observancia y disposiciones del tratado quedó limitada al término de cuatro meses que han expirado ya. Desde que se asumió la resolución del gobierno peruano de poner fin al tratado, creí de mi deber tomar medidas de precaución para que los privilegios que en él se conceden a la bandera y mercancías del Perú cesasen en Chile al mismo tiempo que los de nuestra bandera y mercancías en los puertos peruanos. ${ }^{\text {II }}$

¿Cuáles fueron los criterios del presidente Orbegoso para anular un acuerdo comercial con un socio estratégico? El Araucano en una edición especial reprodujo los argumentos peruanos, los cuales tenían como objetivo lo siguiente; "volver al Callao su pasada consideración y preeminencia. Por las bases de aquél tratado quedaba siempre el Callao tributario de Chile". ${ }^{2}$

El Araucano, Santiago de Chile. 28 de octubre 1836. 


\section{R E V I S T A A N G E L U S N O V U S}

El estado chileno era conservador y el desarrollo de un proyecto liberal en uno de sus vecinos más próximos y con quien mantenía vínculos comerciales recíprocos, era inconcebible por eso promovía que la apertura comercial fracasara interviniendo en las decisiones internas del Perú. El proyecto confederado preocupaba seriamente a nuestros vecinos, pero no solo a Chile sino también a Argentina. El presidente Rosas en un manifiesto publicado en I837, señala que Santa Cruz intentaba:

en los delirios de su insensato orgullo, resucitar el pensamiento atrevido de la Confederación SudAmericana y como si los derechos del genio pudieran usurparse, como si la elevación y magnanimidad del héroe le perteneciesen, sabíase que osaba el caudillo acometer la empresa que el inmortal y malogrado General Bolívar vio fracasar ante la opinión de la América. ${ }^{13}$

La relación entre Rosa y Santa Cruz era pésima, siempre se acusó al general boliviano de pretender unificar el norte argentino a Bolivia, azuzando a la población a rebelarse contra el gobierno central que los tenía en el olvido. El más claro evento social contra el gobierno argentino fue la revolución de Salta de 1833 donde se evidenció según las autoridades argentinas la activa participación de Santa Cruz. Por ese motivo, era necesario acabar con la confederación Perú-Boliviana porque ahora ya no sólo atentaría contra la integridad de la nación Argentina sino que Chile y Ecuador veían peligrar su independencia por las ambiciones del protector del Perú. Aunque el verdadero enemigo del naciente estado confederado fueron los emigrados peruanos a Chile, quienes apoyaron las guerras contra la confederación.

\section{Guerra de Puertos}

El reglamento de comercio para el estado Sud-peruano promulgado por Santa Cruz, expresa la preocupación por el mejoramiento de los puertos del estado confederado para que estos puedan competir con Valparaíso que había modernizado sus instalaciones a fin de dominar el Pacifico sur. Por lo tanto, el reglamento de libre comercio, estaba dirigido no solo a modernizar los puertos peruanos sino también a quebrar la hegemonía naciente del puerto chileno por lo cual se otorgó beneficios tributarios a todos los barcos que anclaran en los puertos del estado confederado sin haber tocado algún puerto del Pacifico:

I3 Manifiesto de las razones que legitiman la declaración de guerra contra el gobierno del general Andrés de Santa Cruz, titulado presidente de la confederación Perú-Boliviana. Buenos Aires, I837, p. 26. 
GONZALES JAUREGUI, Yobani Maikel (...) USP - Ano IX, n. I4, p. 67-97, 2018

Toda clase de frutos y efectos extranjeros que se introduzcan por buques nacionales con procedencia directa del país que lo produce, pagaran una quinta parte de los derechos de introducción en documentos del crédito nacional, y el resto conforme a este Reglamento. ${ }^{14}$

Andrés de Santa Cruz afirmaba que era necesario aplicar estas medidas a fin de evitar que Chile siguiera subordinando al Perú, perjudicando la libertad de su comercio y por ende su desarrollo. La situación era tan negativa para el puerto del Callao, que los barcos provenientes de Estados Unidos, Inglaterra o Centroamérica no desembarcaban ningún producto en el Callao por el alto costo de sus derechos de aduanas, incluso los comerciantes peruanos tenían que ir a Valparaíso a comprar productos comerciales para luego venderlos en el Perú. ${ }^{\text {ss }}$ Por ese motivo, para contrarrestar los efectos negativos de la anterior política conservadora, el nuevo reglamento de comercio gravaba de manera distinta a todo aquel barco que anclara en otros puertos del Pacifico que no sean del Estado confederado:

Los efectos y frutos que vengan de Europa, Asia, Buenos-Aires y Norte-América, que hayan tocado antes en cualquiera puerto del Pacifico, que no sea de los pertenecientes a aquellos estados que componen la Confederación Perú-Boliviana, serán gravados con otro derecho igual aquel que le corresponde por el presente Reglamento y este segundo derecho o gravamen será pagado en documentos de toda especie del crédito nacional. ${ }^{16}$

Incluso Santa Cruz procuró el crecimiento del puerto de Arica, estableciendo una aduana común para Bolivia y el Estado Sud Peruano señalando que "no se cobrará impuestos más que un solo derecho de todos los efectos importados o exportados que se importen para Bolivia o para este Estado, el cual será partible por mitad entre ambas Naciones”. ${ }^{17}$ Todas estas medidas buscaban el crecimiento de la economía del Estado Confederado que se encontraba en crisis. En el año de I8 88 el puerto de Paita era declarado por el presidente Orbegoso como depósito para los productos neutrales y fabricados en México, Centroamérica, Nueva Granada y Ecuador, también será puerto de reembarque de dichos productos para Europa, Asia, África, Estados Unidos, Uruguay, Brasil y Oceanía. Todas estas medidas tenían el claro interés de acrecentar la economía liberal en el Perú. Para Chile estas medidas no tendrían efecto positivo porque el comercio directo no favorecerá al Perú, pues los buques extranjeros

Is SANTA CRUZ, Oscar. Op. cit, p. 226.

I6 Reglamento de Comercio Nacional... Op. cit. p. 3.

17 SANTA CRUZ, Oscar. Op. cit, p. 478. 


\section{R E V I S T A A N GELUS N O V U S}

no van a venir solo para comerciar con el Perú y que estas medidas eran un ataque directo a Chile.

En su manifiesto de I840, Santa Cruz nos revela su intención de lograr que el Callao recobre el primer lugar en el pacifico sur y desde su perspectiva ello no se lograba sólo con el reglamento del libre comercio. La creación de los almacenes de depósito en el puerto de Arica, tenía la clara finalidad competir en las mismas condiciones con Valparaíso, que hasta ese momento tenía el control comercial del Pacifico sur. Pero no sólo se buscaba el crecimiento del puerto de Arica sino mejorar principalmente el puerto del Callao, que había perdido su preeminencia por los recargados derechos de aduanas, almacenaje, tonelaje y anclaje que se pagaban.

Estas dificultades en el Callao facilitaron el crecimiento de Valparaíso y revertir esta situación era complicada por la permanente inestabilidad política del Perú y el accionar de los proteccionistas que bloqueaban cualquier proyecto librecambista. En este sentido, Santa Cruz promovió una modernización del primer puerto, reparando los almacenes, construyendo otros más amplios, se construyó un camino de fierro del puerto a la aduana y se hicieron varios cambios en las atenciones para agilizar los trámites, se buscaba devolverle al Callao el esplendor que nunca debió perder.

Otra de las medidas liberales del gobierno confederado fue la firma de tratados de libre comercio con Inglaterra y Estados Unidos. En el caso de los ingleses el tratado brindaba una reciproca libertad de comercio "los ciudadanos y súbditos de los dos países, respectivamente tendrán libertad para ir libre y seguramente con sus buques y cargamentos, a todos los parajes, puertos y ríos, en los territorios antedichos”. ${ }^{18}$ También señala que se mantendrán preferencias arancelarias y que no se impondrá prohibición alguna a la exportación o importación del producto natural, producciones o manufacturas de los territorios de la confederación o de Inglaterra.

El tratado con Estados Unidos tenía los mismos derechos comerciales que el tratado con Inglaterra, poniéndole énfasis en el tema del contrabando, decomisando toda la mercadería no declarada, así como también "toda manufactura preparada y formada expresamente para hacer la guerra por mar o por tierra". ${ }^{19}$ Es interesante anotar que el tratado no toleraba la participación de uno de los firmantes en apoyo a una nación enemiga con la cual se mantengan un conflicto bélico. El tratado tendría vigencia de I2 años, sin embargo, una vez derrotada la confederación, el general Gamarra anuló dichos tratados y lo remplazó

Tratado de amistad, comercio y navegación celebrado entre la Confederación Perú-boliviana y el Reino Unido de la Gran Bretaña. I837.

Tratado de amistad, comercio y navegación. I837. 
GONZALES JAUREGUI, Yobani Maikel (...) USP - Ano IX, n. I4, p. 67-97, 2018 por un tratado con Chile. El general Andrés de Santa Cruz afirma que estas medidas librecambistas fueran vistas con disgusto en Santiago, por eso:

Se empeñó (Santiago) en declarar y continuar, pérfida y alevosamente, una guerra asoladora con el objeto de adquirir predominio naval en el Pacifico, de excitar disturbios en nuestro seno, protegiendo las traiciones y los traidores, para embarazar nuestros arreglos, para cortar vuelo a nuestra prosperidad. $^{20}$

En otra parte de su manifiesto Santa Cruz pone énfasis en el programa del Estado confederado que buscaba fortalecer los diversos aspectos de la economía como:

Infundir en las amortiguadas venas de la agricultura la vida y robustez de las que habían privado la guerra externa y las disensiones intestinas; restituir a la minería su antiguo esplendor; reanimar el comercio con una legislación liberal y generosa; identificar su existencia con los grandes intereses de la sociedad; impregnar, en fin, todas las ramificaciones de la cosa pública en ese espíritu de justicia universal, que es el gran distintivo de la civilización moderna, y la más segura garantía de la ventura de los pueblos...

El Gabinete de Santiago no intervino en nuestros negocios domésticos sino con el fin de impedir que los Estados de la Confederación comerciasen directamente con todos los pueblos de la tierra; y temiendo que perdiese Valparaíso la supremacía mercantil, de que estaba años hacía en posesión, por consecuencia de los desórdenes del Perú y de los errores económicos de su administración. ${ }^{2 \mathrm{I}}$

Líneas arriba se puede percibir la frustración de Santa Cruz ante el fracaso de la confederación y de su apuesta liberal. Además, de señalar cuáles fueron las verdaderas intenciones chilenas, que buscaban impedir a toda costa el crecimiento peruano que, afortunadamente para sus intereses, tuvo en los propios peruanos sus principales aliados para destruir quizás el mejor intento de integración entre dos países con una misma raíz histórica. De esta forma quedaba sepultada la puesta en práctica de un régimen liberal, que tendrá que esperar la llegada del guano y un crecimiento económico mundial para triunfar, sin duda, la economía perdió la oportunidad de crecer y de igualar a quien sería décadas más tarde su rival más encarnizado. A su vez estos hechos demuestran la falta de visión de caudillos como Gamarra, que privilegio sus apetitos personales, antes que la visión de país que si tuvo el general Santa Cruz, sus rasgos indudablemente eran autoritarios, más intento organizar un estado en crisis, con mucha oposición interna y externa. Lo cierto es que durante la

Ibidem, p. I25. 


\section{R E V I S TA A N G E L S N O V U S}

Confederación Perú-Boliviana, el crecimiento económico producto de la política librecambista fue real, así lo demuestran las siguientes cifras:

Cuadro I. Exportaciones 1830-1839

\begin{tabular}{c|cccccc} 
Años & $\mathbf{1 8 3 0}$ & $\mathbf{1 8 3 4}$ & $\mathbf{1 8 3 6}$ & $\mathbf{1 8 3 7}$ & $\mathbf{1 8 3 8}$ & $\mathbf{1 8 3 9}$ \\
\hline Azúcar & & $\mathrm{I} 20$ & 384 & $\mathrm{I} 2,389$ & $\mathrm{I4,900}$ & \\
Salitre & $\mathrm{II}, 200$ & & & 165,369 & & \\
Algodón & & & & 18,769 & $30,4 \mathrm{I2}$ & \\
Lana & & & & 26,000 & 31,008 & \\
Cobre & & & 6,722 & 14,946 & 32,472 & 50,000
\end{tabular}

Fuente: Santa Cruz, Oscar. El general Andrés de Santa Cruz. Gran Mariscal de Zepita y el Gran Perú. La Paz. 1924 .

Las cifras son expresadas en quintales y un tema importante que se desprenden de ella, es el incremento de las exportaciones de azúcar. Hasta i835 el principal mercado era Chile y el nivel era muy bajo comparado con las exportaciones durante la Confederación, este crecimiento en varios ámbitos del comercio, generó las reacciones más enconadas del gobierno chileno, que veía el éxito de una propuesta librecambista en su vecino norteño. Sin embargo, no fueron las únicas rentas que experimentaron crecimiento, las cifras por derechos de aduana, también son importantes. Incluso en puertos donde la recaudación era pobre se llegó a triplicar los ingresos.

Cuadro II. Rentas de Aduanas

\begin{tabular}{l|cccc|} 
Puertos & $\mathbf{1 8 3 3}$ & $\mathbf{1 8 3 5}$ & $\mathbf{1 8 3 6}$ & $\mathbf{1 8 3 7}$ \\
\hline Callao & & $\mathrm{I} .265,513$ & $\mathrm{I} .298,022$ & \\
Huanchaco & 68,293 & & $48,653^{22}$ & 67,536 \\
Lambayeque & & 3,336 & & 46,504 \\
Arica & & & $1.232, \mathrm{I} 34$ & $\mathrm{I.286,134}$ \\
Paita & & & 48,030 & $56, \mathrm{I} 40$
\end{tabular}

Fuente: Santa Cruz, Oscar. El general Andrés de Santa Cruz. Gran Mariscal de Zepita y el Gran Perú. La Paz. 1924 .

Debemos tener en cuenta que las rentas de aduanas crecieron a pesar que el reglamento había liberado de arancel a los barcos que llegaban primero a puertos del Estado Confederado. En el caso del puerto del Callao su aumento era ligero, pero en el caso de 
Huanchaco, Lambayeque y Paita que estaban ubicados en el estado nor-peruano, sus rentas mejoraron notoriamente. Por ejemplo, las rentas de Huanchaco reportaron en dos años I833 a I835, la suma de 68,293 pesos y solo en el año de I837 superó esa cifra, Lambayeque en solo dos años fue el puerto de mayor crecimiento y Paita, que, según Santa Cruz, nunca había alcanzado la suma de 28 mil pesos, mejoró significativamente. A continuación, presentaremos una relación de barcos que entraron al puerto del Callao en I837:

\section{Relación de barcos que entraron al Puerto del Callao I837}

\begin{tabular}{|c|c|c|c|c|c|c|c|c|c|c|c|}
\hline Nación & Feb. & Mar. & Abr. & May. & Ag. & Set. & Oct. & Nov. & Dic. & Total & Toneladas \\
\hline UK & 4 & 9 & IO & I4 & I4 & I7 & II & I8 & I5 & II2 & 17,526 \\
\hline USA & & 7 & 4 & 3 & 3 & 6 & 5 & 5 & I & 34 & 8,962 \\
\hline Ecuador & IO & 8 & 5 & 6 & IO & 7 & 6 & 8 & 7 & 67 & 7,729 \\
\hline Francia & 4 & 2 & 2 & 2 & I & 2 & 3 & I & 2 & 19 & 5,172 \\
\hline Centroame. & 2 & 4 & & 2 & 3 & & 2 & I & 3 & I7 & 2,465 \\
\hline Nueva Gr. & 4 & 2 & I & & I & 2 & & 3 & I & 14 & 1,268 \\
\hline Sud-per. & & I & I & & I & 3 & I & & 3 & IO & 517 \\
\hline Sardas & I & & I & & I & I & I & I & 2 & 8 & 2,718 \\
\hline Danesa & & I & & & & & & & I & 2 & 508 \\
\hline Hambur. & & I & & & & 2 & I & & & 4 & 1,268 \\
\hline Prusia & & & & I & I & & & & & 2 & 720 \\
\hline Bélgica & & & & & & I & & I & & 2 & 262 \\
\hline Chile & & & & & & & & I & I & 2 & 348 \\
\hline México & & & & & & & & I & I & 2 & 149 \\
\hline
\end{tabular}

Fuente: Colección Félix Denegri Luna: FDL: 0377. Archivo Instituto Riva Agüero

En el cuadro de importaciones tenemos algunos datos interesantes, el primero, es la primacía comercial de Inglaterra, la firma del tratado de libre comercio, beneficio directamente el comercio con el Reino Unido. En el caso de Estados Unidos si bien su participación era importante no llegó a ser determinante en la economía del Estado Confederado, quizás a Santa Cruz le importaba más las relaciones con Inglaterra, porque podría actuar no solo como un mercado sino para la protección del proyecto. Sin embargo, el hecho más relevante es la presencia de Ecuador, no existió ningún tratado de libre comercio con el vecino norteño, pero era necesario otorgarle ventajas porque si no hubiese sido perjudicial que se una al eje Santiago-Buenos Aires. El primer paso para este hecho fue levantar la prohibición que se tenía para comerciar con Ecuador a raíz de la peste de cólera que asoló a ese país. Posteriormente se fortalecieron los lazos políticos y económicos, sin olvidar que, una vez caída la confederación, Ecuador fue el lugar de refugio de Santa Cruz. También tenemos la relación de barcos que salieron del Callao en el mismo año:

\section{Relación de barcos que salieron Puerto del Callao 1837}

\begin{tabular}{l|llllllllll|} 
Nación & Febr. & Mar. & Abr. & May. & Ag. & Set. & Oct. & Nov. & Dic. & Toneladas \\
\hline UK & I2 & 8 & 7 & I6 & I3 & I3 & I4 & I5 & IO & I8, I75
\end{tabular}


R E V I S TA A N G L U S NOVU S

\begin{tabular}{|c|c|c|c|c|c|c|c|c|c|c|}
\hline USA & 4 & 4 & 7 & 3 & 2 & 5 & 3 & 5 & 3 & 9,597 \\
\hline Ecuador & 7 & 8 & 7 & 7 & II & 7 & II & IO & 5 & 7,474 \\
\hline Francia & I & 3 & 4 & I & I & 2 & I & 3 & 3 & 4,554 \\
\hline C. A. & & 2 & 4 & 3 & 2 & 2 & I & 2 & & 2,097 \\
\hline Nueva Gr. & & 3 & 3 & 2 & 2 & 3 & & & 2 & 1,642 \\
\hline Sud-per. & & I & 2 & 2 & & 3 & I & I & 6 & 1,620 \\
\hline Sardas & & & & 2 & & & 2 & 2 & & $\mathrm{I}, 8 \mathrm{OI}$ \\
\hline Danesa & & & I & & & & & & & 306 \\
\hline Hambur. & & & I & & & I & 2 & I & & $I, 270$ \\
\hline Prusia & & & & & I & & & & & 360 \\
\hline Bélgica & & & & & & & I & I & & 262 \\
\hline Chile & & & & & & & & & I & 338 \\
\hline
\end{tabular}

Fuente: Colección Félix Denegri Luna: FDL: 0377. Archivo Instituto Riva Agüero

Como vemos no sólo fue alto el ingreso de mercaderías, también las exportaciones crecieron de forma considerable, siendo los principales productos el azúcar que durante muchos años fue el producto bandera de nuestra comercio con Chile, aun así el nivel era pobre comparado a la bonanza durante la confederación. Pero no sólo fue el azúcar, Inglaterra inició el proceso de compra del salitre peruano y fue uno de los productos que creció de forma considerable en la balanza comercial, aunque casi nuestro principal ramo de exportaciones eran productos primarios

\section{Agustín Gamarra y la prensa Chilena en contra del Proyecto Confederativo.}

El general Agustín Gamarra y el Andrés de Santa Cruz obtuvieron su reconocimiento por su participación en las guerras de independencia. En el caso de Gamarra se reconocía una gran influencia en la ciudad del Cusco de donde era originario y posteriormente fue prefecto, hecho que permitió crear redes clientelares, que incluían políticos, familiares, amigos, etc. Estas redes serán su soporte para la oposición al proyecto confederado del general Santa Cruz, que tenía a Arequipa como su principal bastión. Lo interesante era que tanto Santa Cruz como Gamarra, no representaban la permanente lucha entre el norte y el sur, sino era la lucha de dos hombres representativos de un mismo espacio: El sur andino.

La oposición entre Gamarra y Santa Cruz, no era algo nuevo desde finales de la década de I820, ambos habían estado cerca del Bolívar y por la tanto, conocían perfectamente la idea de la Federación de los Andes. Cada uno trató de implementarla de acuerdo a su ideario. Si bien los dos proyectos aparentemente eran personalistas, el de Santa Cruz era más orgánico que el proyecto autoritario de Gamarra. La confederación Perú-boliviana, fue así un proyecto que buscó unificar políticamente al Perú y Bolivia, existiendo dos perspectivas, una 
GONZALES JAUREGUI, Yobani Maikel (...) USP - Ano IX, n. I4, p. 67-97, 2018 liderada por Gamarra quien buscaba una clara influencia de Perú sobre Bolivia, porque desde su óptica:

El Perú nunca ha necesitado de Bolivia, Bolivia siempre ha sido del Perú. El Perú no necesita de nadie para existir, y Bolivia jamás podrá salir de la clase de pupila del Perú. Bolivia, existe por el Perú: su independencia y libertad son dadas por esta nación generosa, y por el esfuerzo de sus hijos respiran esos miserables pueblos bajo la sombra de un jefe nacido en Bolivia, y por consiguiente son mandados más bien por un padre y hermano que por una autoridad. Sin el Perú, Bolivia estaría respetando y aun adorando a los negros de Colombia que trasladaron desde el Orinoco sus galpones guineos para manejarlos como a unos degradados colonos. Estos son los bienes que el Perú ha llevado a Bolivia, y sería una degradación y una infamia que el último pescador del Desaguadero buscase incorporación en aquella pequeña y miserable patria. ${ }^{23}$

Sin lugar a duda, para Gamarra la separación del Alto Perú y el Bajo Perú había sido perniciosa, y más aún la presencia extranjera que generó esta división. Por lo tanto, era necesario integrarlas nuevamente. En ese sentido, Gamarra tenía un desprecio por Sucre y Bolívar y todo lo que ellos representaban, la negritud es puesta en tela de juicio como signo de inferioridad, así como lo va a hacer el origen andino de Santa Cruz. ${ }^{24}$ Para Gamarra, ningún gobernante de Bolivia había logrado imponer autoridad por su visión paternalista y lo que se requería era mano dura en el gobierno. Por ese motivo, era indispensable que él llevara a cabo su proyecto de unificación de Perú y Bolivia.

\section{Gamarra vs Santa Cruz}

Gamarra se vislumbra como un personaje en constante complot contra el régimen establecido en Bolivia, en una misiva fechada el 28 de setiembre le escribió a su gran amigo el general de La Fuente que "si en este caso hago uso de la fuerza, ya sea para invadir, o cuando menos para ocupar los pueblos de nuestra pretensión”. ${ }^{25}$ Por lo visto, la intención de invadir Bolivia y anexarla al Perú era parte de la agenda política de Gamarra, ${ }^{26}$ solo debía esperar una

23 GAMARRA, Agustín. "Epistolario". Recopilación y Prólogo y notas de Alberto Tauro del Pino. Lima: UNMSM, I952, p. I87.

24 Para una mejor explicación del racismo de la elite limeña al origen andino de Santa Cruz revisar: MÉNDEZ, Cecilia. Indios si, Incas.

25 GAMARRA, Agustín. Op. cit., p. 207.

26 Las intromisiones de Gamarra a Bolivia no eran una novedad en I827, invadió Bolivia para ponerle fin al gobierno del general Sucre, porque según Scarlett O'Phelan, el sentido del concepto de Independencia que manejaba Gamarra era distinto al que se concebía. Para él, la presencia de extranjeros en el poder era una amenaza a la misma independencia. Por lo tanto, era necesario prescindir de su presencia. Esta 


\section{R E V IS TA A N GEL U N O V U S}

oportunidad. Por su parte la misión Álvarez había logrado acercamientos con sectores descontentos con el régimen de Santa Cruz, que buscaban la anexión boliviana al Perú. La comunicación de Álvarez con los conspiradores fue interceptada por el régimen de Santa Cruz, una de esas cartas, enviadas con un nombre falso a Mariano Ángel Moscoso expresaba lo que era un secreto a voces:

La refusión de ambas repúblicas parece muy importante y ventajosa, especialmente a Bolivia, que a Ud. y todos los sensatos convienen en que no puede existir por sí sola. Más, es una obra que debe meditarse con mucho acuerdo, y ponerse en planta por unos medios muy seguros. Las dos referidas cartas de V. las he remitido, originales al señor Gral. Gamarra de cuya cooperación debe aguardarse todo. Mientras él contesta.... V. y los buenos patriotas, y hombres de influjo deben estarse haciendo de elementos que puedan servir eficazmente en su oportunidad, contando con cuanto pueda yo valer, y comunicándome individualmente cuanto se trabaje, y pueda ser conducente a facilitar el apoyo que. Se pretende del Perú. ${ }^{27}$

Estos hechos motivaron una protesta del general Santa Cruz, solicitando el retiro del ministro Álvarez, a lo cual el gobierno peruano accedió. La misión creemos no había fracasado del todo, su verdadero interés no se hallaba en buscar solución a los impases sino ahondar la crisis en Bolivia, lo que permitía la intervención directa del general Gamarra. Por lo tanto, la política del doble juego tendrá que seguir su curso, a pesar de las fundamentadas sospechas del general Santa Cruz al complot en su contra. Un mes después ocurrió un incidente que llevó al general Gamarra a dirigirle una carta al general Santa Cruz donde afirmó que no debía desconfiar de los movimientos militares que se realizan en Puno, porque no existía la intención de invadir Bolivia. Alegando que no tendría razón para invadir al país altiplánico:

\footnotetext{
¿No ha estado en otro tiempo Bolivia en mi poder y con deseos en la mayor parte de su población de unirse al Perú? ¿No la dejé en estado de constituirse libre y espontáneamente? [...] ¿Una nueva invasión me presentaría mayor gloria, mayor ejemplo de desprendimiento? ¿Los más de sus generales y sus jefes, no me propusieron unirse al Perú, y yo los rechace con una grata generosidad? [...] ¿Le falta al Perú algo para existir? Nada; luego ¿Qué podría buscar en Bolivia? Solo la amistad, que no se consigue con el cañón, ni las bayonetas. Cálmate un poco: reflexiona incidentes pasados: acuérdate lo
}

determinación, señala O’Phelan: "puso fin a los planes de Bolívar relativos a la confederación de los Andes”. O’PHELAN GODOY, Scarlett. Santa Cruz y Gamarra: El proyecto de la Confederación y el control Político del Sur Andino. Guerra, Región y Nación. La Confederación Perú-Boliviana. ROJAS, Carlos Donoso y BERDECHESKY, Rosenblitt, Jaime. Editores. Universidad Andrés Bello y Centro de Investigaciones Diego Barros Arana. Santiago de Chile: 2009, p. 26.

TAYLOR, Phillip Parkerson. Andrés de Santa Cruz y la Confederación Perú- Boliviana. 1835-1839. La Paz: Librería Editorial Juventud, 1984, pp. 6o-6I. 
GONZALES JAUREGUI, Yobani Maikel (...) USP - Ano IX, n. I4, p. 67-97, 2018 que le debes al Perú; y tú, tú solo serás quien proporcione esa amistad, único objeto de los peruanos. Ojalá llegue el día de que a orillas del Desaguadero, nos presente el acto más solemne. ${ }^{28}$

Su afán de desvirtuar las acusaciones en su contra, lo llevaron a presentarse como el salvador de la unidad boliviana al haber rechazado la unión propuesta por diversos sectores de Bolivia. Incluso su tono es soberbio al señalar que el Perú no necesita del país altiplánico, su gloria personal no requiere ninguna invasión ni conquista. Por el contrario, quien está en deuda permanente con el Perú es Santa Cruz, por lo que le pide calma y que espera la realización del encuentro en Desaguadero. La entrevista entre los líderes se llegó a concretar en el mes de diciembre a propuesta de Santa Cruz, quien buscaba disminuir la tensión con el Perú.

La ronda de conversaciones tuvo un lapso de 3 días, la propuesta peruana giró en torno a la firma de un tratado comercial, "reduciendo impuestos de bienes importados desde un país por el otro al 4 por ciento, y un tratado de límites”. ${ }^{29}$ Este último punto fue el discordante, el Perú solicitaba el territorio de Copacabana a cambio otorgaría un espacio en Tarapacá, la contraparte boliviana requería el puerto de Arica, obviamente para Gamarra dicho pedido era desmesurado, incluso su respuesta fue "negativa, pero de un modo bastante acalorado". Este impasse mantenía oportunamente la tensión entre Perú y Bolivia, creemos que ni tanto Santa Cruz como Gamarra querían distender las relaciones, el mismo presidente boliviano expresaba sus dudas porque dice:

he reconocido en el Gral. Gamarra las mismas intenciones y el mismo espíritu traidor que desplegó en el año 28. Habituado en la baja intriga y en la falsa política presume sorprendernos como antes, y sus objetos son que Bolivia mandada por un Cacique sólo sea colonia del Perú. ${ }^{30}$

A pesar de las desconfianzas mutuas los dos caudillos mantuvieron las relaciones, no exentas de permanentes acusaciones de boicots. Para Basadre, la presencia de Gamarra evitó que las intrigas de Santa Cruz desmembrasen el territorio nacional, practicando un nacionalismo autoritario, ${ }^{31}$ con un gran apoyo de los sectores conservadores de la sociedad limeña. Hasta que, en el año de 1835 , trabajaron conjuntamente en generar una corriente rebelde en contra del nuevo presidente José Luis Orbegoso, ${ }^{32}$ cada uno trataba de ganar partidarios a su proyecto unificador. En ese momento surgió el movimiento rebelde del

TAYLOR, Phillip Parkerson. Op.cit., p. 63.

Ibidem, p. 63.

BASADRE, Jorge. Historia de la República. Tomo II. Lima: Editorial Universitaria, 7 à edición., p.56. 


\section{R E V I S TA A N G E U S N O V U S}

general Salaverry, que amenazaba seriamente los planes de Gamarra y Santa Cruz. Si bien la desconfianza era latente entre ambos, la presencia de Gamarra en Bolivia como asilado político, permitió a Santa Cruz tejer una relación de intereses con Gamarra, a quien se le permitió el regreso al Perú para combatir a Salaverry y trabajar a favor del proyecto confederado.

Una vez en el Perú, escribió a Santa Cruz señalándole que su presencia había logrado que sectores federalistas de Cusco y Puno se colocasen a su orden y le sugirió que envié armamento para derrotar a las fuerzas de Orbegoso y Salaverry y marchase hacía Arequipa porque lo ideal sería terminar con la "contradicción de Cusco y Puno, es decir si estos son Salaverristas, los arequipeños serán federales”. Sin embargo, la presencia de Gamarra en el Perú no significó la concretización de lo acordado en el encuentro en Chuquisaca. A pesar de señalar que "es falso cuanto le han dicho a U. de que yo trato con Salaverry". ${ }^{33}$ El acuerdo con Salaverry, era casi un hecho, producto del cálculo político de Gamarra que avizoraba que Santa Cruz prefería pactar con Orbegoso, quien era más dócil a someterse a las ambiciones del díscolo general cusqueño.

A pesar de negar su vinculación con Salaverry su cercanía con el joven general era real, tal como lo expresó en su misiva del 29 de julio de i835, donde llamó al general Salaverry ahijado y pidió que vaya hacia el Cusco a ponerse frente al ejército que había logrado formar y que lo esperaba ansioso e incluso señaló Gamarra ${ }^{34}$ que estos hechos fortalecerán sus lazos en bien del país. Ese mismo día en otra carta al general Santa Cruz, afirmaba que él no "sabe urdir mentiras y en todo marcho con honradez", 35 e insistió que los comentarios que hablan de un pacto con Salaverry son absolutamente falsos. Como se puede apreciar Gamarra ofrecía a los dos "una misma cosa, auxilio a cada uno y su cooperación para acabar con el otro". ${ }^{36}$ Santa Cruz al conocer este hecho expresó que no creía encontrar un hecho similar ni en los anales del bajo imperio. ${ }^{37}$

Los tratos de Gamarra y Santa Cruz no eran los únicos que tenían fluidez, el general Orbegoso mantuvo una comunicación permanente con Santa Cruz, en una misiva fechada el 17 de febrero de 1834 pone en conocimiento los planes que Gamarra tenía para dar un golpe de estado a su gobierno y colocar al general Bermúdez como sucesor "El de enero dispuso hacerme asesinar y obligar a la Convención a nombrar a Bermúdez. Yo no contaba con un solo soldado, no tuve más recurso que probar fortuna, y dar un golpe sorpresa a la fortaleza del Callao, tuve la ventura de apoderarme de ella y poner en el deber a su guarnición. Una hora después estalló la revolución del general Gamarra en esta capital” Archivo Félix Denegri LunaFDL: 0592.

33 GAMARRA, Agustín. Op. cit. p. 263. SAN CRISTÓBAL, Evaristo. El Gran Mariscal Luis José Orbegoso. Su vida y su obra. Gil S.A. Editores, I94I, p. 74.

35 Ibidem, p. 73.

36 SANTA CRUZ, Oscar. Op.cit, p. 97.

37 Ibidemt, p. 97. 
GONZALES JAUREGUI, Yobani Maikel (...) USP - Ano IX, n. I4, p. 67-97, 2018

Podríamos pensar que Gamarra usaba el doble discurso producto de sus cálculos políticos. Por un lado, su trato con Santa Cruz aseguraba un retraso de cualquier acción bélica en su contra logrando aglutinar un ejército que sumaría al grupo que Salaverry comandaba, de esta manera derrotarían a Santa Cruz. Por el otro lado, una vez lograda la victoria podría deshacer la alianza con Salaverry y vencerlo fácilmente, de esta manera sin obstáculos lograr poner en marcha su proyecto confederado. Aun así, dicho plan no sería nada fácil de concretar porque Santa Cruz no confiaba en Gamarra, por ese motivo sella su pacto con Orbegoso.

El mismo general Santa Cruz afirmaba que la traición era parte del actuar del general cusqueño, traicionó a San Martin, Bolívar, La Mar, La Fuente, a la Convención en I834, también lo hizo con Salaverry y con el mismo general Santa Cruz en i835, luego se volvió el más entusiasta colaborador de una empresa sostenida contra su país natal que buscaba "vapulear y saquear a sus compatriotas, para deprimir la industria y el comercio del Perú, para cegar todos los canales de la prosperidad nacional; para humillar, en fin, a su patria y someterla a los caprichos y a las combinaciones de un gabinete rival, interesado en su ruina”. ${ }^{38}$ Santa Cruz afirma que Gamarra no tardará en traicionar a sus nuevos aliados, porque la traición la lleva en su ser.

De esta forma para Santa Cruz era menos perjudicial un trato con Orbegoso, quién aceptó la propuesta de confederar los dos países porque asumía que el protector boliviano era el mal menor. Era más perjudicial la presencia de Gamarra y Salaverry que la de Santa Cruz, teniendo en cuenta que la idea federativa era muy fuerte en el sur, los diarios arequipeños habían desplegado una intensa campaña a favor del federalismo y Santa Cruz había ligado su imagen al federalismo y al libre comercio, elementos claves donde reposaría el desarrollo arequipeño.

Por lo tanto, aceptar el federalismo era ponerse de parte de una necesidad del progreso y de la salida de los principales responsables del caos y desgobierno. El aceptar la confederación también implicaba ponerle fin a las constantes intromisiones de Santa Cruz en la política peruana, que según Orbegoso solo buscaba “Turbar la tranquilidad del Perú, con el objeto de dividirlo para debilitarlo”. ${ }^{39}$ En suma, el esfuerzo del proyecto de Santa Cruz de ser visto como la tabla de salvación para el Perú tuvo el éxito esperado por su ideólogo.

Aunque Gamarra seguía siendo el escollo natural para un proyecto que se percibía por diversos sectores como la invasión boliviana al Perú, así como la amenaza para la independencia de otras repúblicas. Entonces no es de extrañar la búsqueda de Chile como

SANTA CRUZ, Oscar. Op. cit, p. 99.

ORBEGOSO, José Luis. Memorias del Gran Mariscal. Don José Luis Orbegoso. Lima: Gil S. A. Editores, I940, p. 86. 


\section{R E V I S T A A N GELUS N O V U S}

aliado para derrotar a la confederación. Desde I836, Gamarra se comunica con Diego Portales, afirmándole que es conocida las ambiciones del general Santa Cruz que "desde el año veinte y nueve ha estado derramando el oro y la seducción más activa para dividirnos y suscitarnos una guerra civil”. ${ }^{40}$

Esta afirmación, era parte de la estrategia de Gamarra para consolidar el apoyo del gobierno de Chile a su causa. Así lo reveló una misiva enviada al general Francisco Vidal, luego del desembarco chileno en agosto de I838, donde expresaba cuál era su estrategia para derrotar al ejército confederado. Primero era reclutar a los soldados veteranos que participaron en la guerra de independencia, en segundo lugar, activar la participación del ejército chileno en calidad puramente de auxiliador.

La aceptación según Gamarra, de la presencia chilena se promovió luego de cerciorarse que no iban a afectar la independencia peruana, también señaló que el general Orbegoso no estaba convencido de la desinteresada participación del ejército chileno "cree (Orbegoso) que el ejército de Chile ha venido con miras perniciosas que dañan la independencia, que dañan el decoro nacional”. ${ }^{41}$ Los juicios vertidos por Gamarra a los comentarios de Orbegoso, nos da la impresión de que su ambición por derrotar al proyecto confederado, lo hacía perder la perspectiva sobre las reales intenciones de Chile para participar a favor de los emigrados. En una misiva enviada al general Domingo Nieto, el general Gamarra señala que esta "persuadido profundamente del desinterés del gobierno de Chile y de la sanidad de sus intenciones en la gran obra de la Restauración del Perú”. ${ }^{42}$ En la misma carta reaccionó furibundamente contra aquellos que afirman que la presencia del ejército chileno era nociva para el Perú y desmiente tajantemente "a quien afirma que mi corazón aún al mando que alguna vez ejercí" 43 .

El gobierno de Chile tenía sus propios temores respecto a la confederación y encontró en los mismos peruanos aliados que sumaban a su interés en truncar la unión de Perú y Bolivia. En una editorial de junio de I837, el Araucano, señalaba que Santa Cruz, está persuadiendo a enemigos de la nación chilena para subvertir el orden interno, siendo una táctica conocida de Santa Cruz "quien sopla el fuego de la discordia protegiendo a los desterrados, subministrándoles armas, facilitándoles invasiones. Iguales pasos dio el Perú, hasta derribar al general Gamarra, dar la mano al estúpido Orbegoso y sacrificar a Salaverry”. ${ }^{44}$

GAMARRA, Agustín. Op.cit., p. 265.

Ibidem, p. 274.

MC EVOY, Carmen y RÉNIQUE, José Luis. Soldados de la República. Guerra, correspondencia y memoria en el Perú. (1830-1844). Lima: Fondo Editorial del Congreso de la República. IRA, 20IO, p. 207.

Ibidem., p. 207.

El Araucano. Santiago de Chile, is de junio de 1837. 
GONZALES JAUREGUI, Yobani Maikel (...) USP - Ano IX, n. I4, p. 67-97, 2018

Era evidente la solidaridad con Gamarra y Salaverry, ellos estaban ubicados en la misma orilla que los intereses del estado chileno, en tanto Orbegoso, veía a Chile como un vecino peligroso y poco leal.

En otra carta Gamarra trataba de persuadir al general Orbegoso que su interés en terminar con la confederación no reviste ambiciones personales, porque no tiene interés en hacerse cargo del mando supremo y que su papel de jefe del ejército lo hace con el mayor de los sacrificios porque el pueblo se hallaba acéfalo. Prometiéndole influir en sus amigos y "en todos los buenos peruanos para que se haga U. nuevamente del gobierno, sería el primero que le rendiría obediencia”.45

La obediencia a sus palabras era frecuentemente desobedecida por Gamarra, creía que ofreciéndole el poder a Orbegoso iba a encontrar su apoyo. Asumía que las ambiciones por el poder dirigían la vida del general Orbegoso, incluso lo conmina a escoger si está de lado de Santa Cruz "capitulando con él la entrega de estos departamentos a su dominación o abrazar cordialmente a sus hermanos los peruanos". ${ }^{46}$ Era obvio que para Orbegoso, todo era una necesidad de Gamarra para ganar adeptos, creía que el Perú podía deshacerse de Santa Cruz sin ayuda extranjera porque:

La idea de sustituir una dominación con otra era insoportable, cuando el mismo General Santa Cruz acababa de darnos una severísima lección demostrándonos que los auxiliares (extranjeros) son aciagos, y acarrean más perjuicios, que los ocasionados por el mal que pretende extirparse. ${ }^{47}$

Orbegoso desistió cualquier trato con el ejército chileno y Gamarra, decidiendo acercarse a Santa Cruz, aunque al final terminó discrepando de él. Aun así, Santa Cruz siempre fue su opción más cercana, porque asumía que el verdadero enemigo del Perú era el gobierno de Chile, que desde su perspectiva "había invadido el país".

\section{La formación de la opinión pública durante la confederación Perú-Boliviana.}

El estudio de la prensa como formadora de la opinión pública ha dado un giro interesante en los últimos años, ya no se busca la revisión del periódico fuera de contexto o aislándolo del espacio en el que fue producido. Por el contrario, las investigaciones se centran ahora en las relaciones de la prensa y sus lectores y como se van generando ideas políticas que 


\section{R E V I S TA A N G E U S N O V U S}

usan al periódico como trinchera ideológica o un espacio de debates permanente. El periódico no es una fuente manuscrita, pero sus datos pueden ser considerados inéditos por el investigador. ${ }^{48}$ Asimismo, es necesario señalar que el estudio de la prensa no se ha permanecido sólo en el plano de las ideas políticas sino ha sido enmarcada desde la historia cultural, Luis Miguel Glave afirma que:

La prensa sería el vehículo primordial de comunicación, seducción, imposición y educación. Sobre periódicos, bandos libelos y carteles se edificaban un sentir y una manera de expresión que daba signos de la construcción de la nación y de las identidades colectivas que la acompañarían. Un discurso y una lucha cotidiana se entretejían en las páginas de esos periódicos que nos sirven de puerta de entrada al mundo andino del siglo XIX. ${ }^{49}$

Es decir, si nos interesa saber como se generaba un discurso sobre la república y la nación es el periódico la clave para entender desde las regiones o los centros del poder como se moldeaba una idea de la república peruana. En esa línea Luis Miguel Glave resalta que los estudios sobre la prensa, incluyen la publicación, la difusión, lectura y recepción, todo esto dentro de una nueva vertiente de la historia cultural. Es desde esta perspectiva de presente y de futuro, que los historiadores vuelven a mirar la prensa periódica del nacimiento de las repúblicas hispanoamericanas..$^{\circ}$ Sin lugar a dudas la prensa significó un nuevo universo narrativo donde se fue gestando una idea de lo nacional:

La prensa encierra pues la historia de una verdadera creación colectiva, la de público y lo nacional en Hispanoamérica. Esa textura cultural, escrita pero que va más allá de la escritura, vino a cristalizar largos desarrollos de sentido, un hilo conductor que trasciende el tiempo y las distancias, que acerca y perdura..$^{\text {II }}$

En las siguientes líneas haremos un breve recuento de las investigaciones sobre el papel de la prensa en los primeros años de la república tanto en Perú y Chile, así como también de los regionalismos existentes en el proceso de la confederación. Uno de los primero trabajos que va en esta línea es el de Jorge Basadre, quien señala que durante el periodo en cuestión existió "una orgía periodística, que al mismo tiempo fue brillante y cenagosa". ${ }^{2}$ En IFEA, IEP, 2004, p 28.

49 Ibidem, p. 53.

so Ibidem, p. 29.

5I Ibidem, p. 54. 
GONZALES JAUREGUI, Yobani Maikel (...) USP - Ano IX, n. I4, p. 67-97, 2018 esta línea podríamos afirmar que la orgia que señala Basadre tuvo un fuerte componente regional, desde el espacio del Cuzco, Charles Walker sostiene que:

La característica más notable de esta literatura, más allá de la cantidad, es su naturaleza fuertemente partidista. Casi todos los periódicos y folletos podrían ser incluidos en el campo conservador o liberal, lo libraban tanto en la prensa como en el campo de batalla. ${ }^{53}$

En la misma línea regional se ubica el trabajo de Luis Miguel Glave, quien sostiene que el estudio de la prensa en la época señalada nos permite entender no solo la publicación sino también "la difusión, lectura y recepción, es parte de un planteamiento renovado como toda la mirada a la sociedad se va perfilando a los ojos de la nueva historia cultural". ${ }^{44}$ Es en esta perspectiva que se enmarca la investigación, desde la historia cultural, no sólo nos interesa conocer el contenido de los diarios sino como se generó su difusión y como fue moldeando la opinión pública, desde el rumor de las plazas hasta las tertulias, chinganas, pulperías y plazas todos fueron espacios de difusión de ideas. La prensa a diferencia de la lectura de los libros, estuvo más cerca de la población, así lo afirma, Marcel Velásquez:

La prensa, motor de la cultura de lo escrito, contribuyó decisivamente a la secularización y modernización de la sociedad mediante discursos políticos y literarios. Mientras el libro seguía siendo una experiencia minoritaria, las hojas y la diversas publicaciones periódicas llegaban a diversos sectores sociales y reinaban en los espacios públicos (cafés, hoteles y pulperías) y se leían y comentaban en el seno de familias, e incluso mediante una escucha atenta eran apreciados por aquella mayoría que no sabía leer. 55

Por ello, asumimos el rol central de la prensa en las opiniones a favor o en contra del proyecto confederado. Desde diversos espacios de la república, la prensa fue generando corrientes de opinión en torno a los intereses de los caudillos que representaban, dejando por debajo el interés de nuestra naciente república. Quizás, esta polarización explique nuestro fracaso como país en los primeros años de instalada la república peruana. Donde no existió un proyecto de país sino intereses personales.

52 BASADRE, Jorge. Historia de la República del Perú. Sétima edición. Lima: Editorial Universitaria. 1983, Tomo. II. pp. 286-287.

53 WALKER, Charles. La orgia periodística: prensa y cultura política en el Cuzco durante la joven república. In: Madrid: Revista de Indias, 200I, vol. LXI, núm. 22I, p. 24.

54 GLAVE, Luis Miguel. La república instalada. Formación nacional y prensa en el Cuzco i825-I839. Lima: IEP, 2004, p, 29.

55 VELÁSQUEZ, Marcel. La república de papel. Política e imaginación social en la prensa peruana del siglo XIX. Lima: UCH, 2009, p. 25. 


\section{R E V IS TA A N GEL U N O V U S}

\section{La prensa chilena y su oposición a la confederación Perú-Boliviana}

La prensa en Chile tuvo un discurso frontal contra la confederación Perú-Boliviana, durante este periodo se multiplicaron los periódicos chilenos, en I836 existían sólo siete periódicos, para I839 aumentaron a 34 periódicos, todos ellos recibían importante subsidio estatal. ${ }^{6}$ Este hecho explica en gran parte que actuaran como voceros oficiales, así lo define Ana María Stuven:

Paradojicamente, el autoritarismo portaliano no silencio a toda la prensa, sino más bien tuvo claridad sobre su importancia como instrumento como manipulación de la opinión pública, entendida esta en un sentido restringido, como un grupo dirigente, obviamente no masivo, que discute y ejerce presión a través de los medios sobre el sistema político. ${ }^{57}$

Sin duda la guerra se inició, alentó y fortaleció en la prensa, ella moldeó la opinión pública de acuerdo a los intereses del gobierno, pero también ejerció presión sobre el mismo para que se tomen decisiones. En ese sentido, Francisco Rojas, afirma que El Araucano se configuró "como el elemento más apropiado para la divulgación de las "verdades oficiales", exponiendo en sus páginas aquellas bases institucionales del régimen portaliano". ${ }^{58}$

Asimismo, se propuso ser el agente moralizador dentro de la naciente organización política del país sureño. En sus páginas podemos visualizar la radicalización del discurso en contra de la confederación, Francisco Rojas analizó el diario durante todo el año de i836, concluyendo que existió un vínculo cercano entre un "suceso particular y la forma en que éste último es capaz de ser utilizado por un medio de comunicación para elevar un discurso público acorde con las necesidades específicas de un gobierno determinado".59 Existiendo diversos ejemplos, siendo el más resaltante la derrota en Paucarpata:

orden y la soberanía de Chile que habían sido atacadas desde el momento en que el Perú dejo de ser independiente, es decir, desde el momento en que fue sojuzgado por el Presidente de Bolivia, y la

STUVEN, Ana María. La palabra en armas: patria y nación en la prensa de la guerra entre Chile y la Confederación Perú-Boliviana, I835-1839. In: La República Peregrina. Hombres de armas y letras en América del sur I80o-I884. STUVEN, Ana María y MC EVOY, Carmen. Editoras. Lima: IEP, 2007, p. 4II. Ibidem, p. 4II. Instructor de la Sociedad Chilena. Actualizando la Pedagogía Cívica. Santiago, i836. In: Guerra, Región y Nación. La Confederación Perú-Boliviana. ROJAS, Carlos Donoso y BERDECHESKY, Jaime Rosenblitt. Editores. Universidad Andrés Bello y Centro de Investigaciones Diego Barros Arana. Santiago de Chile. 2009, p. II8. 
GONZALES JAUREGUI, Yobani Maikel (...) USP - Ano IX, n. I4, p. 67-97, 2018 razón y la justicia exigían que se redujese a sus antiguos limites un poder que en medio de las relaciones de paz y amistad se había manifestado alevosamente hostil contra nosotros. ${ }^{60}$

El general Blanco Encalada alegó que la firma del tratado era producto de una serie de errores, el primero fue confiar en las palabras del general de La Fuente, quien nunca consiguió reunir un ejército respetable, y que la idea estar en Arequipa fue errada, debido a que no existieron provisiones, ni tampoco población a favor de la causa chilena, todos habían emigrado. De esta forma, al establecer el gobierno provisorio, solo quedaron el general La Fuente como presidente, Felipe Pardo y Aliaga como ministro general y Ramón Castilla como prefecto de la ciudad. Sin embargo, señalaba Blanco Encalada todo fue transformándose en un caos por la falta de recursos para la subsistencia del ejército, en esas circunstancias:

En situación tan apurada y crítica, desprovistos de medios de movilidad, de subsistencia de vestuario competente para atravesar la cordillera, con un enemigo superior al frente ¿Qué movimiento ofensivo podía yo tentar? ¿Qué éxito podía prometerme de buscar al enemigo? ¿A un enemigo poderoso dueño de todas las posiciones ventajosas que a cada paso proporciona una sierra para combatir, aun siendo en inferioridad de numero? ¿No hubiera la ejecución de un proyecto tan desatinado e irracional atraído la destrucción total del ejército? ¿Aprovechaba este inútil sacrificio a la causa que defendíamos? ¿Importaba al honor de la madre patria el exterminio de tres mil de sus mejores hijos? Respondan, no los militares instruidos, sino los hombres más ajenos de la profesión de las armas con tal que tengan sentido común y buena fe. Está, pues, demostrado que no podía obrar ofensivamente sobre el enemigo sin contrariar las reglas más vulgares del arte de la guerra. ${ }^{61}$

Si bien para Manuel Blanco Encalada la negociación que emprendió con el general Santa Cruz, fue para evitar un inútil derramamiento de sangre y que en el fondo era su única opción, en el vecino del sur las cosas se encrisparon más. Así lo reflejó este editorial de El Araucano, luego de la firma del tratado de Paucarpata:

(...) Al expresar nuestro juicio sobre el Tratado de Paucarpata tenemos la satisfacción de ser meros intérpretes de la sensación unánime de desaprobación y disgusto que ha producido en todos los pueblos de la república que han tenido la noticia de él hasta ahora. Y en efecto, ¿bajo qué otro aspecto pudiera mirarse si lo sancionase la nación, sino como un pusilánime y vergonzoso abandono de todas las justas demandas que hemos hecho al jeneral Santa Cruz? (...) No hai en todo el tratado una sola cláusula favorable a Chile. Aquellas mismas que se nos presentan con cierto aire de equidad, bien examinadas, dan bastante cabida a pretextos que las harán en gran parte ineficaces - se estipula en el

6o El Araucano. Santiago de Chile, 22 de diciembre de 1837.

6I ENCALADA, Manuel Blanco. p. I4. 


\section{R E V I S T A A N G E L S N O V U S}

artículo $5^{\circ}$ que los intereses mercantiles de esta república serán considerados en el Perú como los de la nación más favorecida. ¿Serían pues abolidas las leyes fiscales dictadas por un espíritu de directa hostilidad contra nuestro comercio? Aunque todo el mundo sabe que el blanco al que se dirijieron fue Chile y que no pueden tener aplicación directa respecto de Chile, ellas hablan ostensiblemente con todas las naciones que tienen puertos en el Pacífico. ¿Quién nos asegura que no se alegará mañana a favor de su continuación, que en someternos a ellas no se nos impone ningún gravamen especial, ni se exige de Chile sino lo mismo a que están sujetas todas las otras naciones que se hallan en nuestro caso ${ }^{62}$

El recelo de Chile se debió a varios factores políticos y económicos, en el primer caso, se señalaba que la confederación rompía el equilibrio del pacifico sur y restablecía el viejo centro del poder colonial hispano, así lo afirmaba el poderoso ministro Diego Portales:

La posición de Chile frente a la Confederación Perú-Boliviana es insostenible. No puede ser tolerada ni por el pueblo ni por el gobierno, porque ello, equivaldría a su suicidio. No podemos mirar sin inquietud y la mayor alarma, la existencia de dos pueblos confederados, y que, a la larga, por la comunidad de su origen, lengua, hábitos, religión, ideas, costumbres, formarán como es natural, un solo núcleo. Unidos estos dos estados, aún cuando no más sea que momentáneamente serán siempre más que Chile en todo orden de cuestiones y circunstancia $[. .$.$] La Confederación debe desaparecer$ para siempre jamás del escenario de América. Por su extensión geográfica; por su población blanca; por las riquezas conjuntas del Perú y Bolivia, apenas explotadas ahora; por el dominio que la nueva organización trataría de ejercer en el Pacífico, arrebatándonoslo; por el mayor número también de gente ilustrada de la raza blanca, muy vinculada a las familias de influjo de España que se encuentran en Lima; por la mayor inteligencia de sus hombres públicos, si bien de menos carácter que los chilenos; por todas estas razones, la Confederación ahogaría a Chile antes de muy poco. ${ }^{63}$

La visión geopolítica de Portales no dejaba duda que el Perú y su unión con Bolivia en un solo ente quebraba la hegemonía de Valparaíso como puerto y condenaba en un futuro inmediato a Chile a ser absorbido por el estado confederado. Portales admitía que el Perú era superior en diversos aspectos, en comercio, riquezas e incluso en intelecto, todos estos hechos preocupaban seriamente a Portales, por ese motivo rechazó, cualquier intento de tratado de paz con Santa Cruz. El poderoso ministro chileno, había creado dos espacios importantes para derrotar a la confederación. Por un lado, el eje externo, que buscaba una unión de Argentina, Ecuador y Colombia para derrotar a Santa Cruz y por el otro lado, reunificar criterios al

62 El Araucano, sin fecha exacta, probablemente de finales de i837.

63 BRANDING, Celia Wu. Generales y diplomáticos: Gran Bretaña y el Perú I820-I840. Lima: PUCP, I993, p. I42. 
GONZALES JAUREGUI, Yobani Maikel (...) USP - Ano IX, n. I4, p. 67-97, 2018

interior de Chile, a través de la prensa y tener un apoyo ciudadano para atacar militarmente a la confederación.

Desafortunadamente para Diego Portales, Ecuador rechazo participar en esta oposición, debido a que obtuvo ventajas económicas inmejorables, siendo el segundo país con mayor comercio con el estado confederado, aunque primero se tuvo que anular la prohibición dada por la epidemia de cólera que asoló al país del norte. En una misiva dirigida al general Domingo Nieto, el protector, le hizo conocer la decisión de Vicente Rocafuerte de otorgar:

Seguridades de sus sentimientos pacíficos y de sus disposiciones de hacer un tratado de amistad y comercio. El general Miller, que debe estar cerca de Quito, hará-lo espero- ese tratado, para que el que va ampliamente autorizado, sin más restricción que la que sea recíproco. Pocos intereses en contradicción podemos tener con Ecuador, y es muy importante a ambos que haya confianza recíproca. ${ }^{64}$

En el caso de Colombia, Francisco de Paula Santander se rehusó a intervenir en la guerra por considerarla un asunto interno de la política peruana. Estos reveses políticos no amilanaron a Diego Portales, que tuvo que hacer frente a los cuestionamientos internos. Por ejemplo, Nicolás Pradel afirmaba en el Barómetro de Chile, que "quienes quieren la guerra son demonios y los que quieren la paz son ángeles”. ${ }^{65}$ Siendo Portales la imagen negativa para un sector de la prensa chilena, así como también:

Es factible pensar que parte de la belicosidad de Portales contra Santa Cruz y su Confederación estaba motivada por un ánimo de provocar sentimientos patriotas entre la ciudadanía, que redundaran en un fortalecimiento de la unidad interna en torno al gobierno y su figura. ${ }^{66}$

Estos sentimientos patrióticos sólo se unificaron a la muerte de Portales, tras el penoso incidente en Quillota, se culpó al general Andrés de Santa Cruz de estar detrás del asesinato del poderoso ministro chileno, ni la expedición Freire había logrado un criterio único ante la Confederación como alcanzó la muerte de Portales. Por otro lado, la imagen que Portales había logrado en el Perú, era de la un dictador que no tenía un apoyo mayoritario para organizar una guerra contra el Perú. El Eco del Norte se refirió a Portales de la siguiente

64 MC EVOY, Carmen \& RÉNIQUE, José Luis. Soldados de la República. Guerra, correspondencia y memoria en el Perú. (I830-I844). Fondo Editorial del Congreso de la República. IRA. Lima, 20Io, p. 497.

65 El Barómetro de Chile, 27 de agosto de 1836.

66 STUVEN, Ana María. La palabra en armas: patria y nación en la prensa de la guerra entre Chile y la Confederación Perú-Boliviana, I835-1839. En La República Peregrina. Hombres de armas y letras en América del sur I80o-I884. Stuven, Ana María y Mc Evoy, Carmen. Editoras. IEP.207.Lima, p. 420. 


\section{R E V I S T A A N GELUS N O V U S}

forma, "como el hombre que con asombro del orbe ha logrado sojuzgar su país, no ha podido considerar sin furor, que el término de nuestras dimensiones interiores era también el de su efímero poder" ${ }^{67}$

Además, se afirma que había militarizado el país sureño, imponiendo su lógica de gobierno, en ese sentido, El Eco del Norte, desmintió a los seguidores de Portales, al señalar que la guerra no era tanto contra el enemigo externo sino "contra los interiores que le amenazan, tan terribles y de tanta magnitud, que solo medidas extremas como esta, pueden salvarlo momentáneamente". ${ }^{68}$ Este comentario, rescata la idea que a Portales lo asesinaron por los problemas internos en Chile y que el asesino, el coronel Vidaurre "no fue más que el órgano de una opinión fuertemente pronunciada; de un sentimiento universal arraigado en los intereses públicos y privados de la nación”. ${ }^{69}$

Desafortunadamente, la muerte de Portales no consiguió amenguar los ánimos belicistas, el tratado de Paucarpata fue considerado una afrenta para Chile, por lo tanto, terminar con el proyecto del general Santa Cruz, era de suma importancia. Se decretó el estado de sitio por la inminente guerra y El Araucano acompañó la publicación del editorial haciendo un llamado a la unidad de los chilenos:

\footnotetext{
La ley que contiene esta resolución es uno de los documentos más honrosos para el Gobierno y para el cuerpo legislativo,... para los legisladores, por la patriótica resonancia... con la mira de afianzar el edificio social de los sacudimientos a que estaba expuesto en la actual crisis. No ha habido un solo voto que rechace el proyecto del Presidente... No ha habido más que una sola opinión, un solo deseo, aniquilarle. El nombre del general Santa Cruz ha sido el grito de nuestra unión parlamentaria... El grito ronco del desorden sale del seno de los representantes del pueblo. Los que han jurado enemistad al Gobierno, porque la han jurado a la nación, pretender ser lo órganos del voto público, y como tales son pintados también por las calumnias del extranjero: los verdaderos órganos del voto público los desmienten a ellos y desmienten al extranjero, formando con el Gobierno un cuerpo compacto e invulnerable para resistir a las revueltas interiores y a la ambición extraña. ${ }^{\circ}$
}

El gobierno de Chile había articulado un discurso uniforme contra la Confederación, se había logrado vencer las resistencias iníciales y el presidente Joaquín Prieto alcanzó el apoyo de los opositores a su gobierno, todos identificaron al general Santa Cruz como el enemigo a vencer y desplegaron todos los mecanismos para alcanzar ese objetivo, la Confederación no debía tener ni un minuto más de vida. Se puede observar a raíz de estos

67 El Eco del Norte. Lima, I8 de febrero de 1837.

68 El Eco del Norte. Lima, 25 de febrero de 1837.

69 El Eco del Protectorado, 22 de Julio de I837.

70 El Araucano, 3 de febrero de 1837. 
GONZALES JAUREGUI, Yobani Maikel (...) USP - Ano IX, n. I4, p. 67-97, 2018

testimonios, que la guerra que inició Chile, nada tenía que ver con la idea de liberarlo de un usurpador, todo lo contrario, el proyecto de Santa Cruz estaba afectando seriamente su economía, su creciente interés hegemónico, o como ellos señalaban, se quebraba el equilibrio geopolítico del pacífico sur. Sólo de esta forma se puede entender el encono del vecino sureño. Niegan que su participación sea por intereses comerciales, porque su economía ha mejorado en el periodo de la guerra contra la confederación. Incluso llegan a ejemplificar los hechos señalando que:

si un malhechor ataca nuestro bienes, y nuestra vida en el silencio de la noche, y no logra más que hacernos una herida mortal ¿cogido infraganti, nos contentaríamos con que pague los daños y perjuicios, dejándole en libertad y en posesión de las armas con que pueda volver a acometernos en la noche siguiente? No hay hombre de sano juicio que conteste afirmativamente..$^{71}$

Es obvio que este ejemplo, justificó que la guerra se mantenga hasta lograr la victoria, que se basaba en la expulsión de Santa Cruz del Perú, porque en reiteradas oportunidades el periódico El Araucano, afirmó que la guerra no era contra el Perú sino contra Santa Cruz, que había perturbado la tranquilidad y la armonía de los países americanos, con el proyecto confederado y que intentaba instaurar una monarquía donde el poder absoluto recaía en el protector. El gobierno de Chile, no cesaba en atacar a la confederación e incluso aceptó la mediación de cualquier nación amiga, pero para aceptar dicha mediación es importante disolver la confederación que ha sido el principal objetivo de levantarse en armas. ${ }^{72}$

Por otro lado, es interesante la comparación que el Araucano realiza de la confederación con la restauración del imperio de los Incas, llegan a comparar a Santa Cruz con Túpac Yupanqui ${ }^{73}$ porque no se conformó con poseer el territorio del Tahuantinsuyo sino que intento conquistar el sur con la expedición Freire. Lamentablemente el nuevo Túpac Yupanqui había visto deshecha su oportunidad. En julio der838, el ánimo belicoso del periódico El Araucano esta candente ad-portas de haber zarpado la expedición chilena al Perú, señala que se va a "vengar el honor de nuestra patria, a cimentar su seguridad, y a sostener las libertades de los pueblos sudamericanos conculcadas o amenazadas por el Usurpador del Perú”. ${ }^{74} \mathrm{Su}$ ánimo de venganza estaba presente, confiando que una victoria le devolverá el orgullo mancillado por el tratado de Paucarpata.

7I El Araucano. Santiago de Chile, 22 de diciembre de 1837.

72 El Araucano. Santiago de Chile, io de agosto de 1838.

73 El Araucano. Santiago de Chile, 8 de junio de 1838.

74 El Araucano. Santiago de Chile, 8 de julio de 1838 . 


\section{R E V I S TA A N G E U S N O V U S}

Lo importante para las tropas chilenas y eso lo rescata en algunas oportunidades El Araucano, es que en el Perú había voces que se encontraban descontentas con el gobierno del protector, incluyendo el grupo de emigrados a Chile que apoyaron decididamente la idea de terminar con el gobierno confederado. Asimismo, El Araucano trató de acercarse al general Orbegoso y desmentir algún interés soterrado en declararle la guerra a la confederación, señalan en reiteradas oportunidades que la guerra era contra Santa Cruz y no contra el Perú, que no se podía dudar de su interés en libertar al Perú de un tirano, porque en el año de i822, las tropas chilenas ayudaron a expulsar a los españoles y que ahora la situación era similar, porque se mantenía al Perú en manos del yugo extranjero. En ese sentido, se había cumplido el objetivo derrotar al tirano y por ende, Chile no tenía ningún interés en apoyar a ninguna facción, ni a caudillos y que el apoyo que brindó a los emigrados solo era circunstancial, señalando a su vez, que así Orbegoso se oponga el ejército chileno permanecerá en el Perú:

\footnotetext{
Si por desgracia nos engañamos, si él persiste en querer que el ejército de Chile se retire de aquel territorio antes de haber extinguido hasta los más leves fragmentos de la confederación, no espere que por nuestra parte se ceda a pretensión tan descabellada.... Es un absurdo, es pretender que hayamos agotado en vano nuestros sacrificios, para ver al tirano recobrar con nuevo vigor su actitud amenazadora y volver a dirigirnos sus ataques con redoblado encarnizamiento. Esto Chile no consentirá jamás.75
}

La victoria final fue festejada por El Araucano, reafirmando una vez más que Chile no tenía ningún interés en poner obstáculos a la prosperidad del Perú por el contrario, hacen votos porque sea rico y floreciente, tampoco "deseamos para nuestros puertos unas ventajas que las que se deben a la naturaleza. $\mathrm{Ni}$ apetecemos privilegios, ni consentiremos en excepciones hostiles. La guerra es imposible entre vosotros y la nación chilena, desde el momento que podamos entendernos mutuamente". ${ }^{76}$

Este discurso conciliatorio dista de los encendidos ataques no sólo a Santa Cruz sino a las medidas económicas que el gobierno del protectorado dictó para mejorar las alicaídas arcas de erario nacional. Chile tenía claros intereses económicos en el Perú y contra el Perú, el sólo hecho que Valparaíso fuese superada por el Callao, generó encendidas críticas a la apertura comercial, rechazando de plano la intervención de las potencias extranjeras en la economía del pacifico sur. Este hecho al parecer fue un discurso para la tribuna porque al caer el proyecto confederado, Chile se convirtió en el principal socio comercial de Inglaterra en esta parte del continente. 
GONZALES JAUREGUI, Yobani Maikel (...) USP - Ano IX, n. I4, p. 67-97, 2018

\section{Conclusiones}

El proyecto confederado del general Andrés de Santa Cruz buscó generar un desarrollo económico liberal. Sin embargo, encontró una fuerte oposición de diversos sectores, el primero encabezado por el general Gamarra, quien se opuso rotundamente al proyecto liderado por Santa Cruz, porque tenía uno propio donde Bolivia estaría bajo la influencia del Perú y no al revés, como en el proyecto de Santa Cruz.

Hemos visto a través de la correspondencia el doble juego de Gamarra con la finalidad de ganar adeptos, incluso tratando de buscar acercamientos a Orbegoso, quien rechaza cualquier acuerdo, por considerarlo el principal responsable del caos y desgobierno y sobre todo por haber traído al Perú a los chilenos en calidad de ejercito auxiliar. Po su parte, el general Orbegoso demostró sus discrepancias con Santa Cruz, a quien calificó como un perturbador permanente de la tranquilidad del Perú y que si había optado por apoyar el proyecto confederado fue por haber presenciado en su viaje al sur un apoyo muy fuerte al federalismo.

La segunda oposición que contaba con apoyo de los peruanos emigrados, provenía del gobierno de Chile, que desplegó una fuerte campaña en contra del proyecto confederado. El éxito de Chile, estuvo en las debilidades internas del proyecto, no por algo los mejores aliados de la expedición chilena no fue Argentina sino los propios peruanos, algunos de ellos apoyaron inicialmente el proyecto confederado como es el caso de Orbegoso. Sin embargo, el autoritarismo del general Santa Cruz, debilitó al proyecto mismo, su poca vocación al respeto de los poderes del Estado sea el Congreso o el Poder Judicial, motivaron críticas de sus aliados, fortaleciendo las oposiciones al proyecto confederado. Por otro lado, los sectores populares sólo eran nominales y no debían tener participación política, se limitarían a participaciones en festividades públicas ${ }^{77}$. No creía en una ciudadanía inclusiva, su base política se encontraba en el ejército. Su liberalismo se expresaba con precisión en materia económica pero lo combinaba con la idea de un Estado Federal y con el ejercicio de una autoridad férrea.

A pesar de estos problemas, lo cierto es que el crecimiento económico del estado confederado fue notorio, generando los recelos de Chile que aprovecho el descontento interno para atacar al proyecto confederado argumentando que el Perú había sido invadido, cuando lo real era su preocupación por el desplazamiento de Valparaíso como primer puerto del Pacifico Sur y su posterior declive económico. Finalmente no debemos olvidar el crecimiento de las rentas de aduanas y de las importaciones y exportaciones que permitieron una mayor captación de rentas para el Estado confederado.

77 ALJOVIN, Cristóbal. ¿Una ruptura con el pasado? Santa Cruz y Constitución. Cultura Política en los Andes. UNMSM-IFEA. Lima, p. 148. 